\title{
The Impact of Family Supportive Supervisor Behavior on Employee's Proactive Behavior: A Study of a Moderated Mediating Effect
}

\author{
Panting Chen \\ School of Management, Jinan University, Guangzhou, China \\ Email: 18173988387@163.com
}

How to cite this paper: Chen, P.T. (2019) The Impact of Family Supportive Supervisor Behavior on Employee's Proactive Behavior: A Study of a Moderated Mediating Effect. Open Journal of Social Sciences, 7, 99-113.

https://doi.org/10.4236/jss.2019.77010

Received: June 7, 2019

Accepted: July 16, 2019

Published: July 19, 2019

Copyright (c) 2019 by author(s) and Scientific Research Publishing Inc. This work is licensed under the Creative Commons Attribution International License (CC BY 4.0).

http://creativecommons.org/licenses/by/4.0/

\begin{abstract}
Based on the theory of social exchange, this study attempts to probe the mechanism of the impact of the family supportive supervisor behavior on employee's proactive behavior, especially to explore the mediating role of the affective commitment and the moderating role of the power distance in Chinese organizational context. After analyzing the samples collected from 305 employees, we found that: family supportive supervisor behavior has a significantly positive effect on employee's proactive behavior; affective commitment plays a partial mediating role between family supportive supervisor behavior and employee's proactive behavior; meanwhile, power distance moderates the relationship between family supported supervisory behavior and affective commitment, and further moderates the indirect relationship between family supported supervisory behavior and employee's proactive behavior through affective commitment. That is, the lower the employees' power distance is, the stronger the mediating effect of affective commitment becomes.
\end{abstract}

\section{Keywords}

Family Supportive Supervisor Behavior, Employee's Proactive Behavior, Affective Commitment, Power Distance, Social Exchange Theory

\section{Introduction}

As the nature of work is continuously evolving, so too are work and family lives becoming increasingly intertwined, creating strain for employees trying to function successfully in both domains. Most employees struggle between work and family responsibilities, and the resulting great pressure has some negative effects 
on their work, including decreased task performance, reduced spontaneity that is beneficial to the organization, and reduced job satisfaction [1] [2]. To solve this problem, organizations have gone to great lengths to assist employees in alleviating the distress caused by work-family conflict, such as providing family-friendly benefits [3]. Yet, research shows that the effects of such benefits, albeit well intended, tend to be quite marginal when they are not accompanied by informal family support from supervisors. In recent years, the key role of supervisors in helping employees cope with work and family demands has attracted more and more attention from scholars [4]. Family supportive supervisor behavior (FSSB), as an informal organizational support, is the supportive behavior of supervisors to employees' families [5], which aims to help employees better fulfill their responsibilities of work and family and improve the relationship between work and family [6]. Previous studies have shown that FSSB has a positive impact on employees' work attitude and behavior, and some scholars also call for strengthening the link between FSSB and work-related results in the future [7].

Although Chinese researchers have begun to pay attention to this field, the relevant research is not much. Although a few studies have shown that family supportive working environment can affect employees' attitudes and behaviors such as job satisfaction, job engagement, turnover tendency and job performance [8]. However, few studies have explored the influence of FSSB on employees' extra-role behaviors in the workplace. As an incentive factor to help employees achieve work-family balance, whether its influence will be further extended to the outcome variable at the further organizational level is worth further discussion. In addition, employees' attitudes and behaviors in the workplace are influenced by many factors, one of which is leadership style, a positive leadership style motivating subordinates to take the initiative. Research shows that transformational leadership leads subordinates to exceed work standards and positively predicts individual innovation behaviors assessed by superiors [9]; Leader-member exchange relationship will have a certain impact on the individual's proactive behavior, and a good leader-member relationship will also stimulate the individual's innovative behavior and constructive behavior [10]. However, if there is a lack of trust and responsibility between leaders and subordinates, the psychological security of subordinates will be reduced and individual initiative will be avoided. This research space still requires considerable attention to further develop our understanding of the explanatory mechanisms linking leadership to employees' behaviors. The model in this study is grounded predominantly in social exchange theory and its immediate correlates (e.g. the norm of reciprocity, equity theory), we aim to examine the influence and mechanism of FSSB on employees' proactive behaviors. This study believes that FSSB, as a positive leadership behavior to help employees fulfill their family responsibilities, will enhance employees' proactive behaviors in the workplace. As an emotional mechanism that drives employees' positive organizational beha- 
viors [11], affective commitment is likely to play an intermediary role in the relationship between FSSB and employees' Proactive behaviors. However, the performance of leadership is often related to its situational characteristics. Different power distance may lead to different sensitivity of employees to FSSB. Therefore, this study will further examine its moderating effect between FSSB and employees' proactive behaviors in the workplace. The research model of this paper is shown in Figure 1.

\section{Theoretical Development and Hypotheses}

\subsection{FSSB and Employee's Proactive Behavior}

Proactive behavior refers to the behavior of an employee who spontaneously changes the situation (introduces new working methods, influences organizational strategies) and/or changes himself/herself (learns new skills to cope with future work demands), emphasizing future orientation and change orientation [12]. For example, employees offer Suggestions to the organization, actively seek ways to improve their work, and solve problems with foresight are the main manifestations of proactive behaviors. There are many factors that affect employees' Proactive behaviors. Leadership behavior, as an important situational variable, plays an important role in predicting employees' Proactive behaviors [13].

Firstly, family support supervisors take the initiative to care about employees' family life, respect and understand employees, and provide supportive resources and services to help employees fulfill their work and family responsibilities when needed. This is an important and attractive resource for employees. According to social exchange theory, one party provides something of great value to the other party, which will prompt the other party to give back [14]. The supervisor's enactment of family-supportive behaviors, a valued resource, acts as a service resource and leads to a response from the employee. However, resources are not exchanged randomly; a resource exchanged in one direction is likely to be reciprocated via a resource that is of the same resource type [15]. Based on Wilson et al.'s resource categorization [16], FSSB is a service resource that will likely be exchanged for another service resource (e.g., task and non-task performance). Moreover, given family-supportive supervisors provide support beyond task performance (e.g., help managing competing priorities, flexible hours), FSSB is likely seen as an extra-role service resource such that it is beyond the normal job requirements of a leader. Therefore, when reciprocating, employees will likely (potentially unconsciously) choose a similar extra-role behavior beyond their day-to-day task performance. That is, employees respond to the "above and

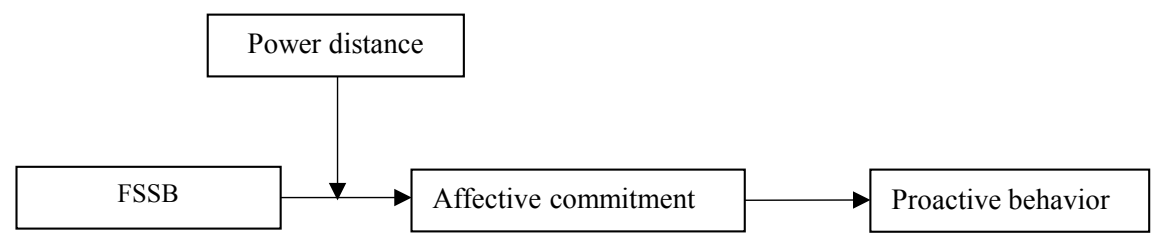

Figure 1. Hypothesized model. 
beyond" leader with "above and beyond" behavior [17]. Secondly, a study by Chalofsky found that there is a relationship between work-life fit and meaningfulness, suggesting that the better work and life merge, the more employees experience meaningfulness at work [18]. FSSB provides employees with sufficient time flexibility to manage their work and family needs, so that employees can ensure the completion of work tasks and the realization of organizational goals while fulfilling their family roles. Such a working environment will enhance employees' sense of work self-efficacy and make them realize the value and significance of work, so as to stimulate employees' strong sense of identity to their own jobs and organizations and to stimulate their intrinsic motivation to work more actively. Thirdly, Ahmadi and Mirsepassi put forward the "performance transfer" effect in their study, that is, when subordinates perceive that the boss puts a lot of energy into their work, they will follow suit and increase their work input [19]. As an extra-role behavior beyond the supervisor's job responsibilities, FSSB reflects the supervisor's extra efforts in work. Employees will imitate the supervisor's input in work to enhance their willingness to actively contribute to the organization. Ultimately, we hypothesize that:

Hypothesis 1: FSSB is positively related to employee's proactive behavior.

\subsection{Mediating Influence of Affective Commitment}

Affective commitment refers to the employees to positive emotional attitude and organization reflects the employees on the degree of emotional attachment, identification and involvement in the organization [20]. As an important agent of the organization, supervisors manage the employment relationship with employees on behalf of the organization [21]. Therefore, the leadership style or behavior of leaders will greatly influence employees' evaluation of their employment relationship with the organization. Employees will think that FSSB not only represents the supervisor's care, respect and recognition for themselves, but also represents the organization's care for their family and work field. In this way, the exchange relationship between employees and supervisors will be developed into the relationship between employees and the organization, and the identity and sense of belonging of employees to the organization will be enhanced. As Panaccio and Vandenberghe noted, employees' perceptions of support from the organization (by way of organizational policies or supportive supervisors) amounts to the workers' recognition that their employer appreciates their contributions to the company's success [22], and is therefore willing to assist and support the employee. The supervisor is the organizational representative with whom the employee interacts on the most frequent basis, so when the supervisor is not supportive of employees' needs (or the employees do not sense that supportiveness), it could logically lead to a decrease in employees' commitment to the organization due to their inability and/or aversion to working optimally under an unsupportive organizational representative. The reverse is also logically plausible: that employees enjoy working for an organization that recognizes and supports its employees, so they in turn become more affectively com- 
mitted to the organization. Substantial research on positive management practices has supported this contention (for a review, see [23]).

Employees with affective commitment will develop a sense of belonging and identity to the organization, which can increase employees' involvement in organizational activities and make them willing to pursue organizational goals and desire to stay in the organization and make their own contributions to the development of the organization. As a challenging active organizational behavior, employees' affective commitment to the organization may be an important factor to predict their Proactive behaviors. Employees with high affective commitment are more likely to recognize the organization's strategies and goals. They will not be limited to completing their daily work, but will actively look for various ways and means to improve the organization's operation. Employees with low affective commitment are more likely to consider that engaging in Proactive behaviors will lead to pressure and risks, and are less willing to make extra efforts to actively change or improve their work. Similarly, Meyer, Paunonen, Gellatly, Goffin and Jackson (1989) likewise found that of the three types of organizational commitment, affective commitment was most positively correlated with important organizational- and individual-level outcomes such as performance and work-family conflict. Similar results were more recently found by Kuvaas and Dysvik (2010), who found that perceived supervisor support was positively predictive of job performance, with Aryee, Chu, Kim and Rye (2013) specifically finding that it was predictive of contextual performance in particular. This stands in line with our discussion regarding the norm of reciprocity as explanatory of the proposed relationship. Therefore, we believe that the organization of the emotion of affective commitment is to promote voluntary behavior motivation, employees in FSSB positive experience, are more likely to have a positive emotions, director of increasing emotional loyalty to the organization, and we hope more emotional attachment to the form of returns, this enhancement of affective commitment expectations and voluntary behavior were positively correlated.

Hypothesis 2: Affective commitment mediates the relationship between FSSB and employee's proactive behavior, FSSB improves employees' level of affective commitment, and thus their level of proactive behavior.

\subsection{Moderating Influence of Power Distance}

Power distance as an important cultural values of the variables, at the national or social level, refers to how a society accept unequal distribution of power in organizations or institutions [24], at the individual level, it reflects the organization of the individual perception of power difference between the superior and the subordinate or values [25]. Power distance in this study refers to the psychological characteristics that reflect the differences of individual values at the individual level. In the study of organizational behavior, power distance is often used as an important regulatory variable to study the relationship between leadership 
behavior and employee behavior [26]. As a role norm, it clarifies the agreed behaviors and obligations of both parties in the relationship and explains the influence of leadership on the attitude and behavior of subordinates [27]. In this study, different power distance is expected to lead to different sensitivity of employees to FSSB, which will lead to different effects of FSSB on employees' affective commitment.

High power distance employees highly revered authority, they expressed fear for leadership, believe that leadership is inaccessible, and leadership is the psychological distance, also won't have too much work outside, so when in trouble, employees in the aspect of family responsibilities tend to suppress their true ideas rather than seeking leadership help. Even in the high FSSB situation, when supervisors provide supportive resources and help to subordinates, employees may not be grateful for such kind of goodwill behavior, so the positive effect of FSSB on employees with high power distance will be weakened. On the contrary, employees with low power distance are less sensitive to power differences between superiors and subordinates and tend to define the exchange with leaders as an interpersonal communication. They believe that leaders are approachable and usually develop a personalized relationship with them [28]. When the family needs help, they will fully seek support and help from the supervisor. At the same time, when they get the resources and support from the supervisor, they will have higher gratitude and sense of obligation to return based on interpersonal reciprocity norms. Such behavior of respecting and caring for employees' families, as well as the organizational atmosphere formed on this basis to help employees achieve work-family balance, will undoubtedly enhance employees' strong identification and dependence on the organization. Studies have also shown that organizational support has a stronger positive impact on the affective commitment, job satisfaction and OCB of individuals with lower power distance [29]. Therefore, this study believes that the positive effect of FSSB on employees' affective commitment will have different influences at different power distance levels. To sum up, we propose the following hypothesis:

Hypothesis 3: Power distance plays a moderating role between FSSB and employee affective commitment. Compared with employees with high power distance, FSSB has a stronger impact on the affective commitment of employees with low power distance.

Based on the above three assumptions, we further propose:

Hypothesis 4: Power distance moderates the indirect effect of FSSB on employees' proactive behaviors through affective commitment. For employees with low power distance, FSSB has a stronger effect on employees' proactive behaviors through affective commitment.

\section{Method}

\subsection{Sample and Procedure}

In this study, questionnaire survey method was adopted to collect data with the 
assistance of human resources department and employees of enterprises. The respondents were mainly employees of enterprises in Guangdong and Hunan provinces, covering the Internet, medical service, machinery manufacturing and other industries. To reduce common method bias, data were collected at two time points. Time point 1 (October 2018), we mainly collected demographic variables, FSSB and power distance level of the subjects, issued a total of 400 questionnaires, and actually recovered 367 valid questionnaires; Time point 2 (November 2018) mainly collects employees' evaluation of affective commitment and initiative behavior of the organization, and also issues 400 questionnaires, and actually collects 341 valid questionnaires. In the two surveys, the last four digits of the mobile phone number were used for matching. After eliminating invalid questionnaires, 305 valid questionnaires were obtained, and the effective recovery rate was $76.25 \%$.

In terms of gender, male accounts for $48.20 \%$; In terms of age, the average age was 35.59 years old $(\mathrm{SD}=7.05)$; In terms of education level, $60.33 \%$ had a bachelor's degree or above; In terms of job grade, grass-roots managers and ordinary employees accounted for $69.18 \%$; In terms of tenure, the average tenure is 6.20 years $(\mathrm{SD}=6.63)$; In terms of marriage and children, $84.92 \%$ were married and $75.41 \%$ had children; In terms of the nature of enterprises, 49.18 percent were private enterprises, and 36.39 percent were state-owned enterprises, public institutions, and government departments.

\subsection{Measures}

The measurement tools used in this study were developed mature scales, and all scales were scored by likert 5-point scale. "1" to "5" respectively represented "strongly disagree" to "strongly agree" or "never" to "frequently". The Cronbach alpha coefficients of each scale in this study are shown in Table 2.

Family supportive supervisor behavior (FSSB) was assessed with the 4-item measure by Hammer, Kossek, Bodner, and Crain (2013). A sample item is "My supervisor makes me feel comfortable talking to him/her about conflicts between work and non-work".

Power distance was assessed with the 6-item measure by Dorfman et al. (1988). A sample item is "I should not have doubts on the decision from supervisors".

Affective commitment was assessed with the 8-item measure by Allen et al. (1990). A sample item is "I would be very happy to spend the rest of my career with this organization".

Proactive behavior was assessed with the 6-item measure by Fuller, Marler and Hester (2012). A sample item is "I would try to bring about improved procedures for the work unit or department".

Control variables. Referring to previous studies [30], we included six control variables, such as gender, age, education level, job grade, length of service, marriage or not, and whether or not there are children are taken as control variables. 


\section{Results}

\subsection{Confirmatory Factor Analyses}

We used Lisrel to conduct confirmatory factor analyses (CFAs) using the maximum likelihood estimation method so we could examine the independence of the study variables. As depicted in Table 1, the goodness of fit statistics of our baseline model (Model IV) shows that our measurement model was appropriate: $\chi^{2} / \mathrm{df}=2.26$, root mean square error of approximation $(\mathrm{RMSEA})=0.06$, non-normed fit index $(\mathrm{NNFI})=0.97$, and comparative fit index $(\mathrm{CFI})=0.97$. This indicates that these five variables have good discriminant validity and represent five different constructs.

\subsection{Descriptive Statistics and Correlations}

The means, standard deviations, and zero-order bivariate correlations reported in Table 2 were in the expected directions and of the expected magnitudes. Among them, FSSB was significantly positively correlated with affective commitment $(\mathrm{r}=0.48, \mathrm{p}<0.001)$ and Proactive behavior $(\mathrm{r}=0.33, \mathrm{p}<0.001)$; Affective commitment is also significantly positively correlated with employees' proactive behaviors $(\mathrm{r}=0.36, \mathrm{p}<0.001)$.

Table 1. CFA results.

\begin{tabular}{ccccccc}
\hline Models & $\chi^{2}$ & $\mathrm{df}$ & $\chi^{2} / \mathrm{df}$ & CFI & RMSEA & NNFI \\
\hline Model IV: FSSB; PD; AC; PB; & 555.74 & 246 & 2.26 & 0.97 & 0.06 & 0.97 \\
Model III: FSSB + AC; PD; PB; & 1013.56 & 250 & 4.05 & 0.95 & 0.10 & 0.94 \\
Model III: FSSB; PD + AC; PB; & 1664.83 & 250 & 6.66 & 0.92 & 0.14 & 0.91 \\
Model II: FSSB + PD + AC; PB; & 2137.01 & 253 & 8.45 & 0.90 & 0.16 & 0.89 \\
Model I: FSSB + PD + AC + PB; & 3826.82 & 252 & 15.19 & 0.83 & 0.22 & 0.81
\end{tabular}

Notes: FSSB, family supportive supervisor behavior; PD, power distance; AC, affective commitment; PB, Proactive behavior.

Table 2. Descriptive statistics and correlations.

\begin{tabular}{|c|c|c|c|c|c|c|c|c|c|c|c|c|c|}
\hline Variables & $M$ & $S D$ & 1 & 2 & 3 & 4 & 5 & 6 & 7 & 8 & 9 & 10 & 11 \\
\hline 1) Gender & 1.52 & 0.50 & - & & & & & & & & & & \\
\hline 2) Age & 35.59 & 7.05 & 0.04 & - & & & & & & & & & \\
\hline 3) Education level & 2.51 & 0.89 & -0.06 & $-0.23^{\star *}$ & - & & & & & & & & \\
\hline 4) Position & 2.03 & 0.76 & -0.01 & $0.82^{* *}$ & $-0.20^{* *}$ & - & & & & & & & \\
\hline 5) Organizational tenure & 6.20 & 6.63 & 0.09 & $0.70^{\star *}$ & $-0.13^{*}$ & $0.56^{* *}$ & - & & & & & & \\
\hline 6) Marriage & 1.85 & 0.36 & 0.05 & $0.56^{* *}$ & $-0.20^{* *}$ & $0.52^{* *}$ & $0.28^{* *}$ & - & & & & & \\
\hline 7) Children & 1.25 & 0.43 & -0.01 & $-0.69^{\star *}$ & $0.24^{\star *}$ & $-0.68^{* *}$ & $-0.34^{* *}$ & $-0.74^{\star *}$ & - & & & & \\
\hline 8) FSSB & 3.57 & 0.77 & -0.04 & $0.18^{\star *}$ & -0.10 & $0.18^{* *}$ & 0.11 & $0.14^{*}$ & $-0.17^{\star *}$ & $(0.81)$ & & & \\
\hline 9) Affective commitment & 3.71 & 0.77 & -0.05 & $0.25^{* *}$ & $-0.15^{*}$ & $0.25^{* *}$ & $0.27^{* *}$ & $0.13^{*}$ & $-0.18^{* *}$ & $0.48^{* *}$ & $(0.94)$ & & \\
\hline 10) Power distance & 3.63 & 0.73 & -0.03 & $0.14^{*}$ & $-0.14^{*}$ & $0.13^{*}$ & $0.15^{* *}$ & 0.10 & $-0.12^{*}$ & $0.45^{* *}$ & $0.50^{* *}$ & $(0.88)$ & \\
\hline 11) Proactive behavior & 3.38 & 0.81 & -0.09 & 0.06 & -0.02 & $0.12^{*}$ & -0.01 & 0.01 & -0.05 & $0.33^{* *}$ & $0.36^{\star *}$ & $0.35^{\star *}$ & $(0.92)$ \\
\hline
\end{tabular}

Note: $\mathrm{N}=305 . \mathrm{M}=$ mean. $\mathrm{SD}=$ standard deviation. Cronbach's alphas $(\alpha)$ are shown in parentheses. Statistical tests were based on two-tailed tests $(\alpha=$ 0.05). ${ }^{*} \mathrm{p}<0.05 .{ }^{* *} \mathrm{p}<0.01 .{ }^{* * *} \mathrm{p}<0.001$. 


\subsection{Testing the Hypotheses}

Model 5 in Table 3 showed that FSSB was positively related to proactive behavior $(\beta=0.34, \mathrm{p}<0.001)$, thus supporting Hypotheses 1 . Model 2 showed that family supportive supervisor behavior was positively related to affective commitment $(\beta=0.45, \mathrm{p}<0.001)$ and Model 6 showed that affective commitment was positively related to proactive behavior $(\beta=0.30, \mathrm{p}<0.001)$. In addition, FSSB was still positively related to proactive behavior $(\beta=0.21, \mathrm{p}<0.01)$. Therefore, affective commitment plays the mediating role between FSSB and employees' proactive behavior $($ Effect $=0.13,95 \%$ Bootstrap $\mathrm{CI}=[0.06,0.23]$ ), thus supporting Hypotheses 2.

According to model 3 , the interaction term (FSSB $\times$ Power distance) was positively related to affective commitment $(\beta=-0.15, \mathrm{p}<0.01)$, which indicates that power distance negatively regulates the relationship between FSSB and affective commitment, and hypothesis 3 is supported. We further conducted simple slopes analysis to better interpret the interaction effect. The interaction effect of FSSB and power distance on employees' affective commitment is shown in Figure 2. When the employee power distance orientation is high, FSSB will trigger the affective commitment of employees $(\beta=0.20, \mathrm{p}<0.01)$, while this positive relationship will be strengthened when the employee power distance orientation is low $(\beta=0.42, \mathrm{p}<0.001)$.

Using the process modeling macro (Hayes, 2013), we tested the indirect effects of FSSB contingent on specific values of power distance (e.g., $1 \mathrm{SD}$ above and below the mean). As reported in Table 4, FSSB had a significant conditional indirect effect on proactive behavior through affective commitment at lower (B $=0.12,95 \%$ confidence interval $[\mathrm{CI}][0.21,0.53])$, mean $(\mathrm{B}=0.09,95 \% \mathrm{CI}[0.16$, $0.42]$ ), and higher ( $\mathrm{B}=0.06,95 \% \mathrm{CI}[0.12,0.23]$ ) levels of power distance. The index of moderated mediation was significant because the $95 \% \mathrm{CI}$ did not include zero ( $\mathrm{B}=-0.04,95 \%$ CI $[-0.09,-0.13])$. Overall, Hypothesis 4 was supported because lower levels of power distance strengthened the indirect effect of FSSB on proactive behavior through affective commitment.

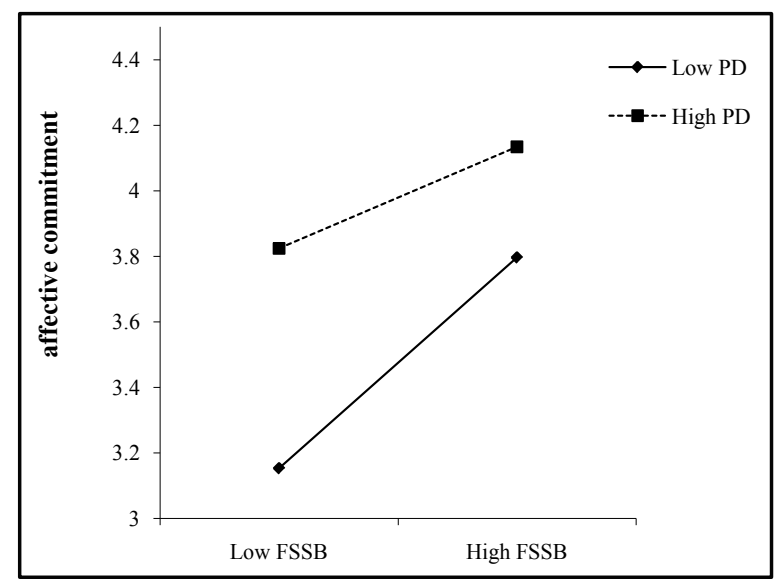

Figure 2. Power distance moderating the relationship between FSSB and affective commitment. 
Table 3. Regression results.

\begin{tabular}{|c|c|c|c|c|c|c|}
\hline \multirow{2}{*}{ Variables } & \multicolumn{3}{|c|}{ Affective commitment } & \multicolumn{3}{|c|}{ Proactive behavior } \\
\hline & M1 & M2 & M3 & M4 & M5 & M6 \\
\hline Constant & 4.01 & 2.45 & 4.02 & 3.34 & 2.15 & 1.41 \\
\hline \multicolumn{7}{|l|}{ Control variables } \\
\hline Gender & -0.11 & -0.08 & -0.06 & -0.13 & -0.10 & -0.08 \\
\hline Age & 0.00 & -0.01 & -0.01 & 0.00 & 0.00 & 0.00 \\
\hline Education level & -0.09 & -0.07 & -0.04 & -0.01 & 0.01 & 0.03 \\
\hline Position & 0.12 & 0.09 & 0.10 & 0.22 & 0.20 & 0.17 \\
\hline Organizational tenure & 0.02 & 0.02 & 0.02 & -0.01 & -0.01 & -0.02 \\
\hline Marriage & -0.05 & -0.07 & -0.08 & -0.15 & -0.17 & -0.14 \\
\hline Children & -0.08 & -0.04 & -0.03 & 0.04 & 0.07 & 0.09 \\
\hline \multicolumn{7}{|l|}{ Main Effect } \\
\hline FSSB & & $0.45^{\star * *}$ & $0.31^{* * *}$ & & $0.34^{\star * *}$ & $0.21^{\star *}$ \\
\hline Affective commitment & & & & & & $0.30^{* * *}$ \\
\hline Power distance & & & $0.35^{* * *}$ & & & \\
\hline FSSB $\times$ Power distance & & & $-0.15^{* *}$ & & & \\
\hline$R^{2}$ & 0.11 & 0.29 & 0.39 & 0.03 & 0.13 & 0.19 \\
\hline$\Delta R^{2}$ & 0.09 & 0.27 & 0.37 & 0.01 & 0.11 & 0.17 \\
\hline$F$ & $4.73^{\star * *}$ & $15.12^{\star * *}$ & $18.65^{\star * *}$ & 1.45 & $5.75^{* * *}$ & $7.80^{* * *}$ \\
\hline
\end{tabular}

Note: $\mathrm{N}=305$; unstandardized coefficients are reported. ${ }^{*} \mathrm{p}<0.05 .{ }^{* *} \mathrm{p}<0.01 .{ }^{* *} \mathrm{p}<0.001$.

Table 4. Conditional indirect effects of FSSB on proactive behavior through affective commitment.

\begin{tabular}{ccccc}
\hline $\begin{array}{c}\text { Moderator } \\
\text { (power distance) }\end{array}$ & B & SE & $\begin{array}{c}\text { Upper limit } \\
95 \% \text { CI }\end{array}$ & $\begin{array}{c}\text { Lower limit } \\
95 \% \text { CI }\end{array}$ \\
\hline-1 SD & 0.12 & 0.39 & 0.53 & 0.21 \\
M & 0.09 & 0.29 & 0.42 & 0.16 \\
+1 SD & 0.06 & 0.25 & 0.23 & 0.12 \\
\hline
\end{tabular}

Note: $\mathrm{N}=305 . \mathrm{M}=$ mean. $\mathrm{SD}=$ standard deviation. $\mathrm{B}=$ unstandardized conditional indirect effect. $\mathrm{SE}=$ standard error. $\mathrm{CI}=$ confidence interval.

\section{Discussion}

First, this study confirms that FSSB has a significant positive effect on employee's proactive behavior. Research conducted by Rank et al. (2007) shows that leadership style is an important situational factor affecting employees' proactive behaviors, which is also verified by many previous studies. For example, positive leadership styles such as inclusive leadership and honest leadership can promote employees to implement proactive behaviors, the abusive or authoritarian man- 
agement style of the leader will inhibit the active behavior of the employees. This study confirms that FSSB, as a positive leadership behavior, also has a positive impact on employees' proactive behavior. For employees, family support supervisors support employees to pursuit of work-family balance and provide a series of services to relieve their work and family pressure. In this kind of caring employment relationship, employees will be more engaged in their work. Based on the principle of reciprocity, employees are more willing to take the initiative to make extra efforts for the long-term development of the organization.

Secondly, this study found that affective commitment plays a part of mediating role between FSSB and employees' proactive behaviors. That is to say, FSSB can not only directly affect employees' proactive behaviors, but also further lead to more proactive behaviors by enhancing employees' affective commitment to the organization. Many studies show that emotional state plays an extremely important role in driving individual behaviors [31]. From the perspective of social exchange, this study reveals the relationship between FSSB and employees' proactive behaviors from the perspective of emotional state, which is also a supplement to existing studies. As the agent of the organization, the supervisor has the most frequent interaction with the supervisor, and the leadership behavior is the direct factor that affects the affective commitment of employees to the organization. The care, support and understanding of the management for employees directly reflect the respect, support and understanding of the organization for employees. Driven by the principle of reciprocity, especially in the Chinese society that attaches great importance to human feelings, it is easier to stimulate employees' gratitude and return, increase their emotional return to supervisors and organizations, and thus increase their initiative in work.

Finally, this study also found that power distance has a moderating effect between FSSB and employees' proactive behaviors. Due to different cultural value orientation, individuals may have different expectations for others' way of getting along with them in the process of social communication, which in turn will affect individuals' way of response [32]. This study introduced the employee power distance under the background of traditional Chinese culture and investigated its contingency effect in the relationship between FSSB and employees' proactive behaviors. The results show that compared with individuals with high power distance orientation, employees with low power distance orientation are more likely to be affected by FSSB. Employees with low power distance orientation tend to get along with supervisors on an equal basis. Therefore, they will fully perceive and take advantage of the good-will support behaviors provided by supervisors to solve their own problems in work and family fields, and enhance their gratitude to supervisors and emotional attachment to their organizations after receiving help, so as to promote their active behaviors; On the contrary, employees with high power distance orientation may be less willing to communicate family problems and seek help with the supervisor due to the large power gap between them and the supervisor, so their emotional attitude and behavioral 
response to the organization are less affected by the supervisor's behavior.

\subsection{Limitations and Directions for Future Research}

This study also has some limitations, which can be improved in the future research. First of all, although the research design of multi-period data collection is adopted in this study to minimize common method bias, it is still not a longitudinal study in a strict sense. Meanwhile, employees' self-assessment is adopted, and the causal relationship between variables is difficult to be completely determined. In the future, we can further study the influence mechanism of FSSB on subordinates' proactive behaviors dynamically through longitudinal follow-up research, or adopt the optimal design combining situational experiment and multi-source mutual assessment questionnaire survey, so as to make the research conclusion more reliable. Secondly, the subjects in this study come from a limited number of regions and enterprises, which limits the external validity of the research conclusions to some extent. In future research, the sample sources should be further expanded to enhance the universality of the research conclusions. Finally, this study takes FSSB as a whole construct to explore its influence mechanism on employees' proactive behaviors. Whether there are significant differences in the influence effect of different dimensions of FSSB on employees' proactive behaviors remains to be further studied in the future.

\subsection{Implications for Practice}

This study also has some practical enlightenment. Given that the FSSB is likely to stimulate employees' initiative in the workplace, organizations should give full play to the role of supervisors in creating family-supportive work environments, meeting employees' needs for belonging and respect, and maximizing employees' work initiative. The organization can implement from the aspect of human resource management practice. First of all, in the process of talent recruitment and selection, we can select the supervisor who is relatively satisfied with FSSB. Secondly, studies have shown that the FSSB is malleable and therefore trainable [33]. Based on this, the organization can increase investment in training. For in-service supervisors, the organization can develop corresponding training courses to help managers learn how to provide better family support for subordinates, and deepen supervisors' cognition and implementation ability of behaviors conducive to employees' work and family relationship. Finally, FSSB can be incorporated into the performance appraisal standard for supervisors, so as to strengthen supervisors' family-supporting behaviors for employees in need of help from the institutional level. Of course, as employees with different sense of power distance have different sensitivity to leadership behaviors, there are significant differences in the intensity of influence of FSSB. Therefore, the organization should not rely too much on the role of FSSB in enhancing employees' affective commitment, and adopt different human resource management methods for different types of employees, so as to increase the possibility 
of their proactive behaviors.

\section{Conclusion}

Based on a questionnaire survey of 305 employees in enterprises, this study explores whether FSSB can promote employees' proactive behaviors in the workplace and its action mechanism. The results show that: 1) FSSB is positively related to employee's proactive behavior; 2) Affective commitment plays a partial mediating role in the relationship between FSSB and employee's proactive behaviors; 3) Power distance has a significant moderating effect on the relationship between FSSB and emotional commitment. When the power distance orientation is low, the relationship between FSSB and employee affective commitment is stronger.

\section{Conflicts of Interest}

The author declares no conflicts of interest regarding the publication of this paper.

\section{References}

[1] Eby, L.T., Casper, W.J., Lockwood, A., Bordeaux, C. and Brinley, A. (2003) Work and Family Research in io/ob: Content Analysis and Review of the Literature (1980-2002). Journal of Vocational Behavior, 66, 124-197.

https://doi.org/10.1016/j.jvb.2003.11.003

[2] Brinberg, D. and Castell, P. (1982) A Resource Exchange Theory Approach to Interpersonal Interactions: A Test of Foa's Theory. Journal of Personality and Social Psychology, 43, 260-269. https://doi.org/10.1037/0022-3514.43.2.260

[3] Bagger, J., Li, A. and Gutek, B.A. (2008) How Much Do You Value Your Family and Does It Matter? The Joint Effects of Family Identity Salience, Family-Interference-with-Work, and Gender. Human Relations, 61, 187-211. https://doi.org/10.1177/0018726707087784

[4] Kossek, E.E., Pichler, S., Bodner, T. and Hammer, L.B. (2011) Workplace Social Support and Work-Family Conflict: A Meta-Analysis Clarifying the Influence of General and Work-Family-Specific Supervisor and Organizational Support. Personnel Psychology, 64, 289-313. https://doi.org/10.1111/j.1744-6570.2011.01211.x

[5] Hammer, L.B., Kossek, E.E., Yragui, N.L., Bodner, T.E. and Hanson, G.C. (2009) Development and Validation of a Multidimensional Measure of Family Supportive Supervisor Behaviors (FSSB) Journal of Management, 34, 837-856. https://doi.org/10.1177/0149206308328510

[6] Odledusseau, H.N., Britt, T.W. and Greeneshortridge, T.M. (2012) Organizational Work-Family Resources as Predictors of Job Performance and Attitudes: The Process of Work-Family Conflict and Enrichment. Journal of Occupational Health Psychology, 17, 28-40. https://doi.org/10.1037/a0026428

[7] Odledusseau, H.N., Hammer, L.B., Crain, T.L. and Bodner, T.E. (2016) The Influence of Family-Supportive Supervisor Training on Employee Job Performance and Attitudes: An Organizational Work-Family Intervention. Journal of Occupational Health Psychology, 21, 296-308. https://doi.org/10.1037/a0039961

[8] Crain, T.L. and Stevens, S.C. (2018) Family-Supportive Supervisor Behaviors: A Re- 
view and Recommendations for Research and Practice. Journal of Organizational Behavior, 39, 869-888. https://doi.org/10.1002/job.2320

[9] Rank, J., Carsten, J.M., Unger, J.M. and Spector, P.E. (2007) Proactive Customer Service Performance: Relationships with Individual, Task, and Leadership Variables. Human Performance, 20, 363-390.

[10] Janssen, O. and Van Yperen, N.W. (2004) Employees' Goal Orientations, the Quality of Leader-Member Exchange, and the Outcomes of Job Performance and Job Satisfaction. Academy of Management Journal, 47, 368-384. https://doi.org/10.5465/20159587

[11] Klein, H.J., Molloy, J.C. and Brinsfield, C.T. (2012) Reconceptualizing Workplace Commitment to Redress a Stretched Construct: Revisiting Assumptions and Removing Confounds. Academy of Management Review, 37, 130-151.

https://doi.org/10.5465/amr.2010.0018

[12] Parker, S.K., Williams, H.M. and Turner, N. (2006) Modeling the Antecedents of Proactive Behavior at Work. Journal of Applied Psychology, 91, 636-652. https://doi.org/10.1037/0021-9010.91.3.636

[13] Den Hartog, D.N. and Belschak, F.D. (2012) When Does Transformational Leadership Enhance Employee Proactive Behavior? The Role of Autonomy and Role Breadth Self-Efficacy. Journal of Applied Psychology, 97, 194-202. https://doi.org/10.1037/a0024903

[14] Cropanzano, R. and Mitchell, M.S. (2005) Social Exchange Theory: An Interdisciplinary Review. Journal of Management, 31, 874-900. https://doi.org/10.1177/0149206305279602

[15] Foa, U.G. and Foa, E. (1974) Societal Structures of the Mind. Charles C Thomas, Springfield.

[16] Wilson, K.S., Sin, H. and Conlon, D.E. (2010) What about the Leader in Leader-Member Exchange? The Impact of Resource Exchanges and Substitutability on the Leader. Academy of Management Review, 35, 358-372. https://doi.org/10.5465/AMR.2010.51141654

[17] Graen, G.B. and Scandura, T.A. (1987) Toward a Psychology of Dyadic Organizing. Research in Organizational Behavior, 9, 175-208.

[18] Chalofsky, N.E. (2010) Meaningful Workplaces: Reframing How and Where We Work. John Wiley \& Sons, New York.

[19] Ahmad, A. and Omar, Z. (2010) Perceived Family-Supportive Work Culture, Affective Commitment and Turnover Intention of Employees. Journal of American Science, 6, 839-846.

[20] Meyer, J.P. and Allen, N.J. (1991) A Three-Component Conceptualization of Organizational Commitment. Human Resource Management Review, 1, 61-98. https://doi.org/10.1016/1053-4822(91)90011-Z

[21] Pan, W., Sun, L.Y. and Chow, I.H.S. (2012) Leader-Member Exchange and Employee Creativity: Test of a Multilevel Moderated Mediation Model. Human Performance, 25, 432-451. https://doi.org/10.1080/08959285.2012.721833

[22] Panaccio, A. and Vandenberghe, C. (2009) Perceived Organizational Support, Organizational Commitment and Psychological Well-Being: A Longitudinal Study. Journal of Vocational Behavior, 75, 224-236. https://doi.org/10.1016/j.jvb.2009.06.002

[23] Mills, M.J., Fleck, C.R. and Kozikowski, A. (2013) Positive Psychology at Work: A Conceptual Review, State-of-Practice Assessment, and a Look Ahead. Journal of 
Positive Psychology, 8, 153-164. https://doi.org/10.1080/17439760.2013.776622

[24] Hofstede, G. (1980) Motivation, Leadership, and Organization: Do American Theories Apply Abroad? Organizational Dynamics, 9, 42-63.

https://doi.org/10.1016/0090-2616(80)90013-3

[25] Dorfman, P.W. and Howell, J.P. (1988) Dimensions of National Culture and Effective Leadership Patterns: Hofstede Revisited. Advances in International Comparative Management, 3, 127-150.

[26] Eylon, D. and Au, K.Y. (1999) Exploring Empowerment Cross-Cultural Differences along the Power Distance Dimension. International Journal of Intercultural Relations, 23, 373-385. https://doi.org/10.1016/S0147-1767(99)00002-4

[27] Kirkman, B.L., Chen, G., Farh, J.L., Chen, Z.X. and Lowe, K.B. (2009) Individual Power Distance Orientation and Follower Reactions to Transformational Leaders: A Cross-Level, Cross-Cultural Examination. Academy of Management Journal, 52, 744-764. https://doi.org/10.5465/amj.2009.43669971

[28] Tyler, T.R., Lind, E.A. and Huo, Y.J. (2000) Cultural Values and Authority Relations: The Psychology of Conflict Resolution across Cultures. Psychology Public Policy \& Law, 6, 1138-1163. https://doi.org/10.1037/1076-8971.6.4.1138

[29] Farh, J.L., Hackett, R.D. and Liang, J. (2007) Individual-Level Cultural Values as Moderators of Perceived Organizational Support-Employee Outcome Relationships in China: Comparing the Effects of Power Distance and Traditionality. Academy of Management Journal, 50, 715-729. https://doi.org/10.5465/amj.2007.25530866

[30] Paustian-Underdahl, S.C. and Halbesleben, J.R.B. (2014) Examining the Influence of Climate, Supervisor Guidance, and Behavioral Integrity on Work Family Conflict: A Demands and Resources Approach. Journal of Organizational Behavior, 35, 447-463. https://doi.org/10.1002/job.1883

[31] Dong, Y., Seo, M.G. and Bartol, K.M. (2014) No Pain, No Gain: An Affect-Based Model of Developmental Job Experience and the Buffering Effects of Emotional Intelligence. Academy of Management Journal, 57, 1056-1077. https://doi.org/10.5465/amj.2011.0687

[32] Markus, H.R. and Kitayama, S. (1991) Culture and the Self: Implications for Cognition, Emotion, and Motivation. Psychological Review, 98, 224-253. https://doi.org/10.1037/0033-295X.98.2.224

[33] Hammer, L.B., Kossek, E.E., Anger, W.K., Bodner, T. and Zimmerman, K.L. (2011) Clarifying Work-Family Intervention Processes: The Roles of Work-Family Conflict and Family Supportive Supervisor Behaviors. Journal of Applied Psychology, 96, 134. https://doi.org/10.1037/a0020927 